Revue

Revue de l'histoire des religions

de Ihistoire des religions

3 | 2018

Varia

\title{
Joseph et Claire YAcouB, Oubliés de tous. Les Assyro- Chaldéens du Caucase
}

Paris, Les Éditions du Cerf, 2015

Anahide Ter Minassian

\section{CpenEdition}

Journals

Édition électronique

URL : http://journals.openedition.org/rhr/9036

DOI : $10.4000 /$ rhr.9036

ISSN : 2105-2573

Éditeur

Armand Colin

Édition imprimée

Date de publication : 1 septembre 2018

Pagination : $547-549$

ISBN : 978-2-200-93188-9

ISSN : 0035-1423

Référence électronique

Anahide Ter Minassian, "Joseph et Claire YACouB, Oubliés de tous. Les Assyro-Chaldéens du Caucase », Revue de l'histoire des religions [En ligne], 3 | 2018, mis en ligne le 01 septembre 2018, consulté le 15 janvier 2021. URL : http://journals.openedition.org/rhr/9036 ; DOI : https://doi.org/10.4000/rhr.9036

Ce document a été généré automatiquement le 15 janvier 2021.

Tous droits réservés 


\title{
Joseph et Claire YAcoub, Oubliés de tous. Les Assyro-Chaldéens du Caucase
}

Paris, Les Éditions du Cerf, 2015

\author{
Anahide Ter Minassian
}

\section{RÉFÉRENCE}

Joseph et Claire YACOUB, Oubliés de tous. Les Assyro-Chaldéens du Caucase, Paris, Les Éditions du Cerf, 2015, 316 p., 21 cm, $29 €$, ISBN 978-2-204-10044-1.

1 Voici un livre écrit à quatre mains, rédigé par deux spécialistes reconnus de la "question assyro-chaldéenne». Depuis trois ou quatre décennies Joseph Yacoub, aujourd'hui professeur honoraire à l'Université catholique de Lyon, sociologue engagé dans la défense des minorités chrétiennes du Proche-Orient, a multiplié les ouvrages sur les Assyro-Chaldéens, sur leur identité ethno-religieuse et leur organisation sociale (notamment dans Babylone chrétienne, Paris, Desclée de Brouwer, 1996; Au nom de Dieu, les guerres de religion d'aujourd'hui et de demain, Paris, J.-C. Lattès, 2002; Qui s'en souviendra? 1915: le génocide assyro-chaldéo-syriaque, Paris, Cerf, 2014). Il est constamment revenu sur l'histoire tourmentée de cette vieille minorité chrétienne. Il a insisté sur les persécutions répétées dont elle a été l'objet, sur le génocide dont elle a été victime avec les Arméniens et les Grecs pontiques dans l'Empire ottoman en 1915 (la couverture du livre est d'ailleurs illustrée par une célèbre photo d'une colonne de réfugiés arméniens en 1915), sur la dispersion des survivants et la création d'une diaspora mondiale dont le réseau s'étend désormais du continent européen aux continents américain et australien. Claire Weibel Yacoub s'est attachée à faire connaître une autre page de l'histoire des Assyro - Chaldéens. Les demandes de leurs diverses délégations venues spontanément à la Conférence de la Paix, à Paris, en 1919, et leur vaine espérance d'un "Foyer national», doté d'une autonomie politique ou administrative dans le cadre des mandats français et anglais imposés aux États successeurs de l'Empire ottoman, au lendemain de la Première Guerre mondiale (Claire 
Weibel Yacoub, Le rêve brisé des Assyro-Chaldéens, l'introuvable autonomie, Paris, Cerf, 2011).

Bien entendu on retrouve en filigrane ces thèmes dans les chapitres de ce nouvel ouvrage dont la thématique porte sur le destin de ce peuple dans un espace géographique particulier, celui du Caucase Sud (Géorgie, Arménie, Azerbaïdjan) où les auteurs sont allés récemment enquêter « sur le terrain » pour y découvrir et attester la présence continue des Assyro-Chaldéens depuis trois siècles. Oubliés de tous. Les AssyroChaldéens du Caucase est en effet un ouvrage dont l'ambition est de démontrer, à travers les vicissitudes de l'histoire, la pérennité ethno-culturelle (langue et religion) des Assyro - Chaldéens dans l'isthme caucasien depuis 1770, date à partir de laquelle ils sont admis en Géorgie par le roi Irakli II. Une histoire plus ignorée qu'oubliée de l'arrivée, corrélative à l'expansion russe au Caucase, de ces "chrétiens orientaux ", groupes de villageois ou d'individus isolés originaires des empires perse et ottoman. C'est par le rappel du rôle central de la Russie, "protectrice des chrétiens » (dans les Balkans, en Orient), mais aussi investie du projet de leur conversion à l'orthodoxie, que Joseph et Claire Yacoub, ont commencé leur livre en résumant les étapes de la conquête russe de l'isthme caucasien au rythme de conflits répétés avec les deux empires musulmans voisins. Une histoire événementielle complexifiée par l'exposé des conditions géopolitiques (persécutions religieuses, asservissements aux tribus kurdes, violences $\mathrm{du}$ pouvoir turc, guerres, disettes etc.) qui ont motivé les premières migrations des Assyro-Chaldéens partis du massif du Hakkari (Turquie), de Mésopotamie ou des rives du lac d'Ourmiah. Des migrations forcées ou volontaires, sanctionnées au XIX ${ }^{\mathrm{e}}$ siècle par des traités internationaux - Turkmantchaï (objet ici d'une étude fouillée), mais aussi Andrinople, Paris, Berlin - auxquelles les Arméniens, à qui l'on doit le terme d'Aïssor qui désigne toujours les Assyro-Chaldéens en Russie, sont étroitement associés. Des traités qui ont sanctionné de véritables échanges de populations qu'il eût été souhaitable de rappeler. Car parallèlement à l'accueil de milliers de chrétiens au Caucase, un à deux millions de Musulmans du Caucase (Tchétchènes, Ingouches, Oubykhs, Abkhazes,...) ont refusé de vivre sous l'autorité du tsar, un souverain chrétien, ont abandonné leurs montagnes et cherché refuge dans les terres du Sultan-Calife ottoman, contribuant à y amplifier les difficultés de la cohabitation avec les populations chrétiennes locales.

3 Le récit historique dense et chargé de toponymes construit par les deux auteurs peut, en l'absence regrettable de cartes, dérouter un lecteur profane. De même, il est regrettable que les auteurs n'aient pas apporté plus de précision sur la dénomination (Assyriens, Chaldéens, Syriaques, Assyro-Chaldéens...) de cette minorité chrétienne parlant l'araméen, «la langue du Christ », ou plus exactement le néo-araméen et ses variantes dialectales, partagée entre plusieurs fidélités religieuses (chrétiens nestoriens jadis émigrés jusqu'en Chine, récemment étudiés par Sébastien de Courtois, syriaques catholiques, syriaques orthodoxes, Assyriens protestants) et dotée de patriarcats. Certes, dans les divers chapitres comme dans les riches notes liminaires, voire dans la bibliographie, on trouve des éléments de réponse à ces questions.

Comme dans leurs ouvrages précédents, les auteurs se sont appuyés sur les témoignages des géographes et des voyageurs occidentaux et russes, des missionnaires catholiques (franciscains, carmes déchaussés, capucins, dominicains) et protestants (anglicans, évangélistes américains). Ils ont souligné leur apport à notre connaissance du monde assyro-chaldéen en émaillant les têtes de chapitres des Oubliés du Caucase de 
citations sensées et judicieusement choisies dans leurs écrits. Aussi le chapitre - trop court - sur les sources assyro-chaldéennes est-il particulièrement précieux. Bien que l'écriture soit inséparable de l'histoire des Églises d'Orient, il a fallu attendre les écoles créées par les missionnaires et leur usage des langues vernaculaires pour assister au renouveau des Assyro-Chaldéens au $\mathrm{xx}^{\mathrm{e}}$ siècle à Ourmiah, à Tiflis ou à Buenos-Aires. Les pages de la revue Kukhva éditée à Ourmiah, où s'est esquissée, au contact de l'Occident, une forme d'introspection " nationale », sont particulièrement bienvenues.

C'est dans la seconde partie du livre avec l'ébauche d'une histoire des Assyro-Chaldéens dans les trois républiques caucasiennes à l'époque soviétique et depuis leur indépendance, que l'on trouve des données inédites. Les auteurs portent un jugement plutôt positif sur la longue période soviétique (1920-1991) qui, malgré la terreur stalinienne, les exécutions, déportations et persécutions religieuses, aurait joué un rôle de conservatoire, tant pour la langue que la religion, des Assyro-Chaldéens au Caucase. Une période au cours de laquelle les Aïssors, sont «reconnus» en URSS comme un «peuple» (narod) nanti de droits culturels et gratifié de quelques belles ascensions sociales. Le chapitre sur les indépendances caucasiennes depuis 1991 se présente sous la forme d'un précieux inventaire, concernant essentiellement la Géorgie, l'Arménie et le Piémont caucasien de la Fédération de Russie. En Arménie, les Aïssors, dont le génocide a été reconnu officiellement par l'État, jouissent ainsi aujourd'hui d'un statut privilégié.

6 La conclusion optimiste de ce livre, écrit avec ferveur, sur le rétablissement des liens de ces Oubliés du Caucase avec l'Église d'Orient a précédé de quelques mois les visites pastorales du pape François durant l'été 2016 dans les républiques caucasiennes. 